\title{
Поведение несвязных грунтов г. Сыктывкара при вибродинамических нагрузках
}

\author{
Вихоть А.Н., Лютоев В.А. \\ Институт геологии ФИЦ Коми НЦ УрО РАН, Сыктывкар, vikhot.anna@mail.ru; lutoev@geo.komisc.ru
}

Аннотация. В настоящее время вопрос обратимого и необратимого изменения структурных связей грунтов, оказавшихся под воздействием техногенной нагрузки, весьма актуален. Рассмотрены закономерности поведения несвязных грунтов г. Сыктывкара при вибродинамических нагрузках, приведены сравнения мелко- и среднезернистых песков разной степени водонасыщения и песков разной фракции одинаковой степени водонасыщения. Наблюдения показали, что мелко- и среднезернистые пески при вибродинамическомнагружении ведут себя идентично, но нарушение структурных связей мелкозернистых песков происходит несколько раньше - при $\mathrm{a}_{\text {кр }}=0.159-0.23$ м/ $\mathrm{c}^{2}$, показатели среднезернистых $-0.162-0.254 \mathrm{~m} / \mathrm{c}^{2}$. Самые устойчивые к уплотнению -маловлажные и влажные мелко- и среднезернистые пески. Водонасыщенные грунты, минуя стадию уплотнения, могут сразу переходить в состояние разжижения. Представлены усредненные графики поведения грунтов, получены усредненные аппроксимирующие полиномиальные функции второй степени и значения достоверности аппроксимации $\mathrm{R}^{2}: 0.988 ; 0.905 ; 0.95 ; 0.969$. Это говорит о точности описания поведения несвязных грунтов при вибродинамических нагрузках и позволяет заключить, что наступление разрушения структурных связей при определенных а кр в несколько большей степени зависит от степени водонасыщения, чем от размера зерен песков.

Ключевые слова:несвязные грунты, степень водонасыщения, вибродинамические нагрузки, критическое ускорение, уплотнение песков.

\section{Noncohesive soils behavior of Syktyvkar through vibrodynamic loads}

Vikhot A.N., Lutoev V.A.

Institute of Geology, Komi SCUB RAS, Syktyvkar,vikhot.anna@mail.ru; lutoev@geo.komisc.ru

\begin{abstract}
At present the issue of reversible and nonreversible changes in structural soils bonds that are under the influence of a man-induced load is highly relevant. The regularities of noncohesive soils behaviorof Syktyvkarthrough vibrodynamic loads were discussed, compares of fine and medium sands of different water saturation degrees and sands of different fractions of the same water saturation degree were made. Observations showed that fine and medium sands had the identical behaviorthrough vibrodynamic loads but the structural bonds disruption of fine sands occured a little earlier - at $\mathrm{a}_{\mathrm{cr}}=0.159-0.23 \mathrm{~m} / \mathrm{s}^{2}$, of medium sands $-0.162-0.254 \mathrm{~m} / \mathrm{s}^{2}$. Low-damp and damp fine and medium sands are the most resistant to compaction. Water-inundated_sands passing the compaction phase can immediately go into a liquefaction state. The average graphs of the soils behavior were presented, the averaged approximating polynomial functions of the second degree and the R-squared value were obtained, $\mathrm{R}^{2}: 0.988 ; 0.905 ; 0.95 ; 0.969$. This indicates the precision in describing the noncohesive soils behavior through vibrodynamic loads and allows to conclude that the initiation of the structural bonds destruction at certain $\mathrm{a}_{\mathrm{cr}}$ depends somewhat more on the water saturation degree than on the sands sizes.
\end{abstract}

Key words:noncohesive soils, water saturation degree, vibrodynamic loads, critical acceleration, sands compaction.

\section{Введение}

В инженерной геологии и геоэкологии в настоящее время вопросы о необратимых изменениях физико-механических и динамических свойств связных и несвязных грунтов от техногенных воздействий приобрели свою актуальность. Их решение требует проведения комплексных исследований. Мы рассмотрим воздействия вибродинамического характера на грунты, отобранные на территории г. Сыктывкара. Здесь первые исследования несущих способностей грунтов начались в 1998 г. в рамках сейсмического микрорайонирования. Геолого-генетический комплекс был разделен на 7 групп с точки зрения пригодности для строительства (Лютоев, 2000); территория города разбита на три типа районов по условиям строительства (Лапицкая, 2000): удовлетворительные, ограниченно при- 
годные и неблагоприятные; определены предельные энергетические уровни уплотнения рыхлых грунтов; описаны закономерности поведения структурно-неустойчивыхгрунтов при вибродинамических нагрузках; приведены сравнительные характеристики результатов этих испытаний грунтов, отобранных на территории города и за его пределами(Лютоев, Вихоть, 2019; Лютоев, Лютоева, 2004; Shushkova, Lutoev, 2013). В виду полученных низких значений первого критического ускорения $\mathrm{a}_{\text {кр }}\left(\right.$ от $\left.0.069 \mathrm{M} / \mathrm{c}^{2}\right)$ для несвязных грунтов и их широкого распространения в геологическом разрезе установим зависимость наступления критического ускорения для данного типа грунтов.

\section{Геологические условия района исследований}

В геологическом строении территории г. Сыктывкара в основном принимают участие грунты ледникового (печорский горизонт) и связанные с ними отложения озерно-ледникового генезиса и осложнены вблизи дневной поверхности аллювиальными наносами и почвенным слоем растительных остатков (Андреичева, 1992; Лапицкая, 2000). Они представлены песками, глинами, суглинками, местами валунными суглинками и супесями. Мощность осадков достигает 50-60 м.

Основной водоносный горизонт - чирвинский аллювиальный горизонт, имеет мощность 1.3-3.4 м.

В геоморфологическом отношении территория г. Сыктывкара расположена в пределах пластово-аккумулятивной платформенной равнины (Геоморфологическое картирование..., 1978). Основные формы рельефа: низкая пойма и террасовый комплекс из 3 надпойменных террас рек Вычегды и Сысолы, флювиогляциальная равнина.

\section{Метод исследований}

Грунты массой 1.2-1.6 кг были отобраны специальными керноотборниками из озерноаллювиальных отложений чирвинского горизонта и аллювиальных и озерно-аллювиальных отложений поймы и 3 надпойменных террас.

Испытания проводились с помощью вибродинамической установки. Она состоит из следующих узлов, закрепленных на железной плите: генератор колебаний АЯЦМ 3.901 .002 ТУ, частотный преобразователь ГРИВ 426449.001, электронные индикаторные часы ИЦ-12.5 с ценой деления 0.01 мм, подставка для крепления датчика смещения, керновый держатель. Градуировка уровня ускорений была установлена с помощью широкополосной сейсмостанции «ZET 048-С». Погрешность в измерениях составила 7-10\%. Время воздействия $-5-7$ с.

\section{Результаты исследования}

Данные испытаний позволили сравнить поведения прочностных свойств несвязных грунтов г. Сыктывкара, вовлеченных в техносферу, выяснить, при каких ускорениях происходит их уплотнение и разжижение и установить, от чего в первую очередь зависит величина уплотнения: от содержания в них свободной воды или от размерности слагающих зерен. Для этого приведем данные в таблице 1 и сравним на диаграммах поведение мелко- и среднезернистых песков разной степени водонасыщения и песков разной фракции одинаковой степени водонасыщения (рис. 1).

В целом, в мелкозернистых песках нарушение структурных связей начинается при значениях $\mathrm{a}_{\mathrm{kp}}=0.159-0.23 \mathrm{~m} / \mathrm{c}^{2}$, первичное уплотнение - при тех же значениях, но влажные пески несколько позже - с $0.254 \mathrm{~m} / \mathrm{c}^{2}$ (рис. 1 a). Вторая стадия уплотнения происходит на отрезке $\mathrm{a}_{\text {кр }}=0.4690 .516 \mathrm{M} / \mathrm{c}^{2}$. Практически сразу наступает разжижение -при сообщении критического ускорения вибраций 0.561-0.624 м/ $\mathrm{c}^{2}$. Отмечается, что первичное уплотнение водонасыщенных мелкозернистых песков может случиться при минимальном значении $\mathrm{a}_{\mathrm{kp}}=0.159 \mathrm{~m} / \mathrm{c}^{2}$, но полное разрушение структурных связей $\left(\mathrm{a}_{\text {крз3}}\right)$ происходит, как и у менее водонасыщенных грунтов, таким образом стадия перехода затягивается и кривая более пологая, но результат уплотнения - средний, 0.7 мм, в виду этого можно отметить водонасыщенные пески, как более неблагоприятные.

Среднезернистые пески испытывают уплотнение и разрушение структурных связей при ускорениях колебаний $0.162-0.254 \mathrm{~m} / \mathrm{c}^{2}, 0.469-0.516 \mathrm{~m} / \mathrm{c}^{2}$ и 0.561-0.624 м $/ \mathrm{c}^{2}$ соответственно, что практически совпадет с диапазонами для мелкозернистых песков (рис. 1 б). Таким образом, можно сделать вывод, что мелко- и среднезернистые пески при вибродинамическомнагружении ведут себя идентично. 
Таблица 1. Уплотнение песков г. Сыктывкара при вибродинамических нагрузках, мм.

Table 1.Sands compactionof Syktyvkar through vibrodynamic loads, mm.

\begin{tabular}{|c|c|c|c|c|c|c|c|c|c|c|c|c|c|}
\hline a, $\mathbf{M} / \mathbf{c}^{2}$ & 0.009 & 0.029 & 0.069 & 0.159 & 0.162 & 0.23 & 0.254 & 0.378 & 0.469 & 0.516 & 0.561 & 0.624 & 0.819 \\
\hline \multicolumn{14}{|c|}{ Пылеватые (laIIč) } \\
\hline $0.5 \leq \mathrm{Sr} \leq 0.8$ & 0 & 0 & 0 & 0 & 0 & 0.11 & 0.22 & 0.33 & 0.44 & 0.77 & 1.28 & 1.36 & 1.73 \\
\hline \multicolumn{14}{|c|}{ Тонкозернистые (aIII-IV) } \\
\hline $0.8 \leq \mathrm{Sr} \leq 1$ & 0 & 0.01 & 0.01 & 0.01 & 0.01 & 0.02 & 0.03 & 0.05 & 0.3 & 0.45 & 0.67 & 0.72 & 0.75 \\
\hline \multicolumn{14}{|c|}{ Мелкозернистые (aIII-IV) } \\
\hline $0 \leq \mathrm{Sr} \leq 0.5$ & 0 & 0 & 0 & 0.01 & 0.01 & 0.09 & 0.09 & 0.09 & 0.16 & 0.21 & 0.24 & 0.3 & 0.32 \\
\hline \multirow{2}{*}{$0.5 \leq \mathrm{Sr} \leq 0.8$} & 0 & 0 & 0 & 0.01 & 0.01 & 0.01 & 0.07 & 0.24 & 0.38 & 0.41 & 0.48 & 0.68 & 0.96 \\
\hline & 0 & 0 & 0 & 0 & 0 & 0.01 & 0.08 & 0.16 & 0.19 & 0.3 & 0.32 & 0.57 & 0.92 \\
\hline \multirow{2}{*}{$0.8 \leq \mathrm{Sr} \leq 1$} & 0 & 0 & 0 & 0.08 & 0.11 & 0.2 & 0.25 & 0.31 & 0.33 & 0.34 & 0.35 & 0.44 & 0.7 \\
\hline & 0 & 0 & 0 & 0 & 0 & 0.01 & 0.03 & 0.06 & 0.13 & 0.2 & 0.26 & 0.4 & 0.38 \\
\hline \multicolumn{14}{|c|}{ Среднезернистые (laIIč) } \\
\hline \multirow{2}{*}{$0 \leq \mathrm{Sr} \leq 0.5$} & 0 & 0 & 0 & 0 & 0 & 0 & 0.07 & 0.08 & 0.09 & 0.1 & 0.15 & 0.25 & 0.39 \\
\hline & 0 & 0 & 0 & 0 & 0.03 & 0.03 & 0.03 & 0.05 & 0.17 & 0.24 & 0.25 & 0.31 & 0.42 \\
\hline $0.5 \leq \mathrm{Sr} \leq 0.8$ & 0 & 0 & 0 & 0 & 0 & 0 & 0.02 & 0.02 & 0.06 & 0.11 & 0.29 & 1.25 & 1.15 \\
\hline $0.8 \leq \mathrm{Sr} \leq 1$ & 0 & 0 & 0 & 0 & 0 & 0 & 0.15 & 0.15 & 0.23 & 0.25 & 0.25 & 0.35 & 0.4 \\
\hline \multicolumn{14}{|c|}{ Крупнозернистые (laIII-IV) } \\
\hline $0.8 \leq \mathrm{Sr} \leq 1$ & 0 & 0 & 0 & 0 & 0 & 0.01 & 0.02 & 0.03 & 0.06 & 0.1 & 0.4 & 0.81 & 1.29 \\
\hline
\end{tabular}

У влажных пылеватых, мелко- и среднезернистых песков первая стадия уплотнения происходит при ускорениях колебаний $0.23-0.254 \mathrm{~m} / \mathrm{c}^{2}$, вторая $-0.516-0.561 \mathrm{M} / \mathrm{c}^{2}$. Разжижение происходит при сообщенииа ${ }_{\text {кр }}=0.624 \mathrm{~m} / \mathrm{c}^{2}$ (рис. 1 г).

Водонасыщенные тонко-, мелко-, средне- и крупнозернистые пески начинают уплотняться

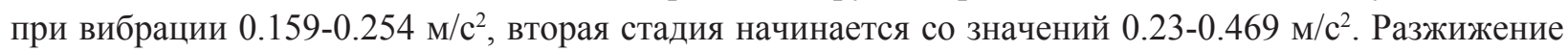
отмечается при $\mathrm{a}_{\mathrm{kp}}=0.624 \mathrm{~m} / \mathrm{c}^{2}$ (рис. 1 д).

На первый взгляд, самые устойчивые к уплотнению - мелко- и среднезернистые пески любой степени водонасыщения. Их $\mathrm{a}_{\text {кр1 }}=0.254 \mathrm{~m} / \mathrm{c}^{2}$ и $\mathrm{a}_{\text {кр3 }}=0.561-0.624 \mathrm{~m} / \mathrm{c}^{2}$. На самом деле, водонасыщенные грунты, минуя стадию уплотнения, что характерно для таких грунтов, могут сразу переходить в состояние разжижения.

На рисунке 1 в и 1 е представлены усредненные графики поведения мелко-, среднезернистых песков разной степени водонасыщения и влажных и водонасыщенных песков разной фракции. По результатам можно утверждать, что мелко- и среднезернистые пески при вибродинамическихнагружениях ведут себя идентично в одинаковых диапазонах $\mathrm{a}_{\text {кр }}$ мелкозернистые пески дают большую величину уплотнения на 0.05-0.07 мм. Заметим, что влажные и водонасыщенные пески разной фракции имеют одинаковый порог критического ускорения разжижения $-0.624 \mathrm{~m} / \mathrm{c}^{2}$. При этом значения уплотнения к этому моменту расходятся: они резко возрастают у водонасыщенных грунтов, разница становится $\approx 0.45$ мм. Вероятно, это обусловлено тем, что водонасыщенные связные грунты в статическом состоянии уже претерпевают некоторое уплотнение за счет давления свободной поры в поровом пространстве. Полученные полиномиальные функции зависимости второй степени дали высокие значения достоверности аппроксимации - более 0.9.

\section{Заключение}

В результате проведенных испытаний распространенных несвязных грунтов на территории г. Сыктывкара получены закономерности зависимости наступления критического ускорения для данного типа грунтов. Анализ показал, что среди них самые устойчивые к уплотнению -маловлажные и влажные мелко- и среднезернистые пески.Водонасыщенные грунты, минуя стадию уплотне- 

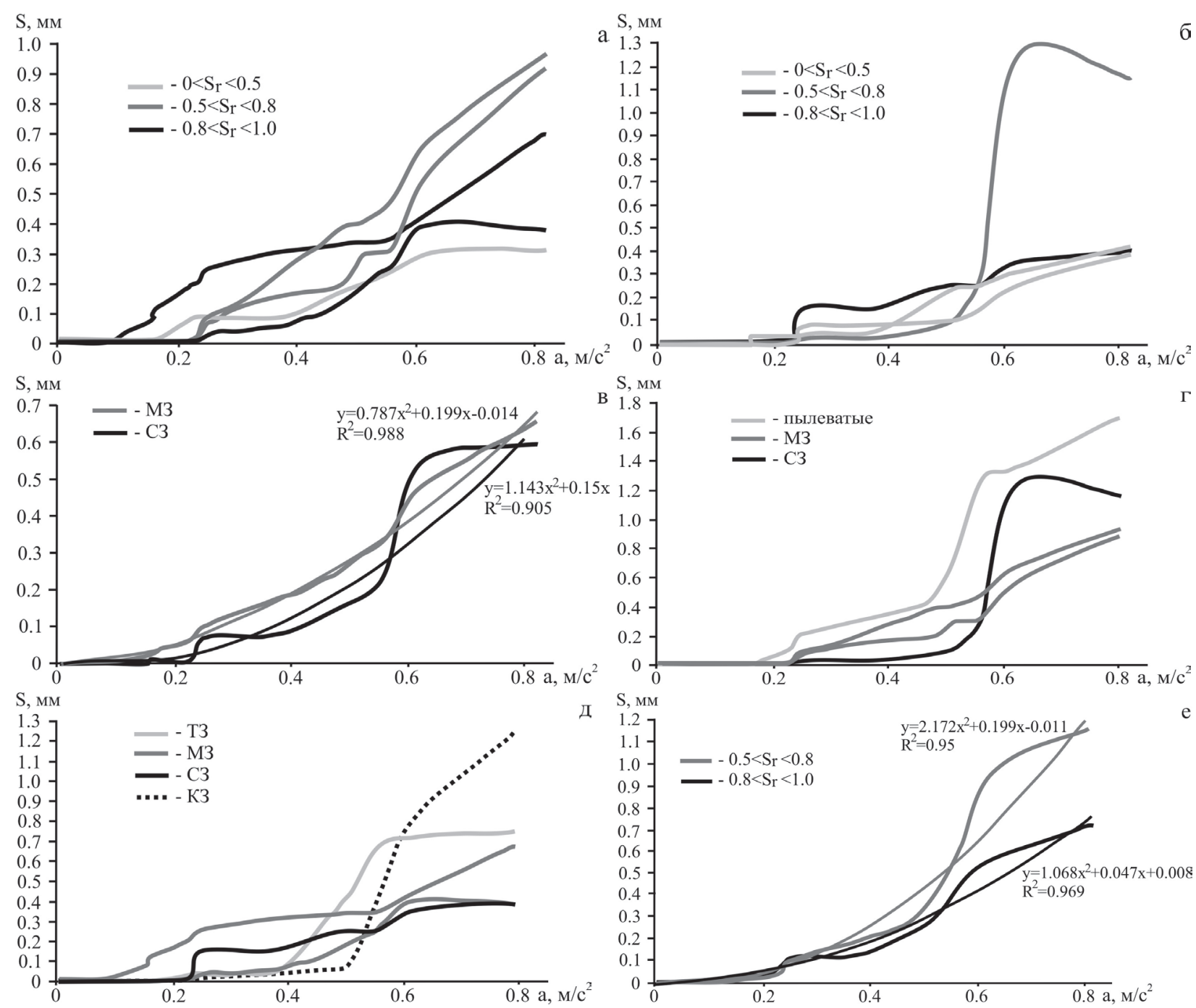

Рис. 1. Функциональные кривые зависимости поведения несвязных грунтов от интенсивности вибродинамической нагрузки: а - мелкозернистых песков; б - среднезернистых песков; в - усредненные графики и линии тренда для мелко- и среднезернистых песков; г - влажных песков разной фракции; д - водонасыщенных песков разной фракции; е - усредненные графики и линии тренда для влажных и водонасыщенных песков.

Fig. 1. Functional curves of dependence on the intensity of the vibrodynamic load of the behavior of noncohesive soils: a - fine sands; b - medium sands; $\mathrm{c}$ - averaged graphs and trend lines for fine and medium sands; $\mathrm{d}$ - wet sands of different fractions; e - water-inundated sands of different fractions; $\mathrm{f}$ - averaged graphs and trend lines for wet and water-inundated sands.

ния, что характерно для таких грунтов, могут сразу переходить в состояние разжижения, поэтому стоит обратить особое внимание на дополнительное изучение их физико-механических свойств при намерении их эксплуатации. Получены усредненные аппроксимирующие функции второй степени отдельно для мелко-, среднезернистых песков, влажных и водонасыщенных несвязных грунтов:

$$
\begin{aligned}
& \text { 1) } y=0.787 x^{2}+0.199 x-0.014 \\
& \text { 2) } y=1.143 x^{2}+0.15 x \\
& \text { 3) } y=2.172 x^{2}+0.199 x-0.011 \\
& \text { 4) } y=1.068 x^{2}+0.047 x-0.008
\end{aligned}
$$

Полученные значения достоверности аппроксимации $\mathrm{R}^{2}: 0.988 ; 0.905 ; 0.95 ; 0.969$ - входят в допустимый предел, следовательно, тренды поведения несвязных грунтов при вибродинамических нагрузках описаны с достаточной точностью. Можно утверждать, что наступление разруше- 
ния структурных связей при определенных $\mathrm{a}_{\text {кр }}$ в несколько большей степени зависит от степени водонасыщения, чем от размерности слагающих пески зерен.

\section{Литература}

1. Андреичева Л. Н. Основные морены Европейского Северо-Востока России и их литостратиграфическое значение. СПб. Изд-во: Наука. 1992. 125 с.

2. Геоморфологическое картирование: сб. ст. (ред. Г.С. Ганешина). М. Изд-во: Наука. 1978. 240 с.

3. Лапицкая В.Ф. Отчет по объекту «Геолого-гидрогеологическая, инженерно-геологическая, геологоэкологическая съемка м-ба 1:50000». Архив Комигеолфонда. 2000.

4. Лютоев В.А. Сейсмическое районирование Республики Коми и микросейсморайонирование г. Сыктывкара: дис. к.г.-м.н. Сыктывкар. 2000. 169 с.

5. Лютоев В.А., Вихоть А.Н. Влияние оползневых процессов и природно-техногенной микросейсмичности на геологическую среду города Сыктывкара. Сыктывкар. 2019. 84 с.

6. Лютоев В.А., Лютоева Н.В. Сейсмическая опасность г. Сыктывкара // Геодинамика и геологические изменения в окружающей среде Северных регионов. Архангельск. 2004. Т. 2. С. 37-38.

7. Лютоев В.А., Лютоева Н.В. Сейсмоустойчивость грунтов северной части Волго-Уральской антеклизы // XIV Геологический съезд Республики Коми «Геология и минеральные ресурсы Европейского Северо-Востока России». Сыктывкар. 2004. Т. 2. С. 29-31.

8. ShushkovaA.N., Lutoev V.A. Ancient glaciation influence on bearing capacity of dispersive soils in the European North of Russia (The Komi Republic) // $4^{\text {th }}$ International Students Geological Conference. Brno. 2013. P. 133. 